\title{
Artes plásticas sob o crivo da formação: a discussão sobre forma e processo social em Gilda de Mello e Souza e Rodrigo Naves
}

\author{
Visual arts under the paradigm of formation: the discussion about form and \\ social process in Gilda de Mello e Souza and Rodrigo Naves
}

\section{Rafael Marino ${ }^{a}$}

Resumo Com base, principalmente, em alguns textos de Rodrigo Naves e Gilda de Mello e Souza, este artigo almeja discutir e escandir as linhas evolutivas da experiência nacional - diversa, porém não alheia ao resto do mundo - figurada via artes plásticas. Pretende-se, assim, discutir, mais especificamente, algumas formalizações dos autores supracitados quanto a formação das artes plásticas no Brasil, a partir do ponto de vista mesmo da forma artística. É preciso dizer que essa discussão entronca, necessariamente, em um dos tópicos centrais do pensamento político e social brasileiro, a saber, o chamado sentido da formação. O qual, de acordo com Otília e Paulo Arantes (ARANTEs; ARANTES, 1997a; 1997b), galvanizou boa parte da vida mental brasileira - com um intuito tanto descritivo quanto normativo - originando grandes esquemas interpretativos os quais, a um só tempo, registravam tendências reais na sociedade e tinham como ponto de fuga a constituição de uma ossatura moderna sustentadora da evolução de nosso meio disforme em direção a uma nação moderna e integrada, à europeia.

Palavras-chave Pensamento político e social brasileiro; artes plásticas brasileiras; formação; Rodrigo Naves; Gilda de Mello e Souza.

Abstract Based mainly on some texts by Rodrigo Naves and Gilda de Mello e Souza, this article aims to discuss and explore the evolving lines of the national experiencediverse but not unrelated to the rest of the world - figured by its corresponding visual

a Mestrando em Ciência Política pela FFLCH-USP e graduado em Ciências Sociais pela mesma instituição, tem experiência na área de Ciência Política, com ênfase em Pensamento político brasileiro e Teoria Política. Desde 2013 participa do Grupo de Pesquisa "Pensamento e Política no Brasil", coordenado pelos Profs. André Singer e Bernardo Ricupero e desde 2015 participa do Grupo "Sequências Brasileiras", vinculado ao Centro de Estudos dos Direitos da Cidadania (CENEDIC-USP), formado por pesquisadores das áreas de Letras e Ciência Política, os quais discutem a atualidade da tradição crítica brasileira. Desde 2016, sob orientação do Professor Bernaro Ricupero, realiza pesquisa de mestrando na qual pretende avaliar a atualidade da categoria de "Sentido da Formação" para o Pensamento Político e Social brasiliero e para a crítica da atualidade. 
arts. The intention is, therefore, to examine more specifically some formalizations of the above-mentioned authors in relation to the formation of visual arts in Brazil, from the artistic form's point of view. It is vital to say that this discussion necessarily meets central topics for the Brazilian political and social thought, for instance, the so-called sense of formation. Which, according to Otília and Paulo Arantes' O sentido da formação (1997), galvanized a substantial part of Brazilian mental life - descriptively as well as normatively - originating interpretative codes that, simultaneously, registered real tendencies in society and had as its central point the constitution of a supporting modern structure of the evolution of our malformed environment in direction to a modern and integrated nation or, in other words, to an European model.

Keywords Brazilian social and political thought; Brazilian visual arts; formation; Rodrigo Naves; Gilda de Mello e Souza.

\section{APRESENTAÇÃO GERAL}

$\mathrm{O}$ artigo em questão tem como objetivo, principalmente a partir da leitura de alguns textos de Gilda de Mello e Souza e Rodrigo Naves, escandir as linhas evolutivas da experiência nacional - diversa, porém não alheia ao resto do mundo ${ }^{1}$ - figurada via artes plásticas. É claro que isso será feito mediado pelas interpretações dos autores, os quais tentarei acompanhar de perto, tendo em vista o que os aproxima e os distância no trato das formas plásticas e de sua autonomia incontrolável (SouzA, 2005, p. 170). De todo modo, antes de adentramos a matéria mesmo do texto, é preciso que indiquemos alguns pressupostos importantes sobre essa discussão e o lugar dela em meio ao Pensamento Político e Social brasileiro.

De acordo com Otília e Paulo Arantes, a categoria de sentido da formação indica a centralidade no pensamento político e social brasileiro de um ideal formativo, baseado em um referencial europeu, de nações integradas. Nota-se que a categoria de formação era uma referência quase que comum à intelectualidade brasileira, até porque, segundo o mesmo Paulo Arantes, "desde os primórdios da nacionalidade, (...) a nossa vida mental sempre girou em torno do esforço, a um só tempo de ilustração e expressão, voltado para a desobstrução das vias de passagem da Colônia para a Nação" (Arantes, 1996, p. 93). Arantes argumenta que a característica marcante desta ensaística brasileira é: tentar, a partir de grandes interpretações assentadas na descrição e no registro de tendências reais na sociedade brasileira, "dotar o meio gelatinoso de uma ossatura moderna que lhe

1 Empresto a fórmula de Schwarz (2014, p. 116). 
sustente a evolução". Tais trabalhos teriam tanto um propósito descritivo, quanto normativo, apontando em direção a uma ideia de formação que corria "na direção do ideal europeu de civilização relativamente integrada - ponto de fuga de todo espírito brasileiro bem formado" (ARAntes; Arantes, 1997b, p. 12).

Entretanto, como não seria possível dar conta de todos os ensaios listados pelos autores, ou ao menos da maior parte deles, e como o propósito aqui não é adentrar mais detidamente nos autores da formação e sim ver como este processo figurou-se nas artes plásticas brasileiras, adianto o passo argumentativo do seguinte modo: se havia uma dificuldade renitente em o Brasil se constituir como uma Nação integrada e voltada para os interesses internos, contando com um Mercado Interno integrado e que conseguiria saciar as carências de sua população - projetos virtuais jogados ao futuro (PRAdo JR, 2011; FURTADO, 1995) - a sua literatura, ou melhor, seu sistema literário formou-se primorosamente, contando com a integração sistemática de autores, públicos e obra (CANDido, 2013, p. 25-43). Prova disso é o surgimento de um autor tão sofisticado como Machado de Assis (CANDIDo, p. 434) e os romances de sua segunda fase, cujo início se deu com Memórias póstumas de Brás Cubas; artífice de uma forma - esta compreendida como conteúdo sócio-histórico sedimentado, segundo a boa tradição dialética (AdoRno, 1970, p. 15) -, em que o "dado" social externo à literatura passa a ser mola propulsora e estruturante do romance (ScHWARZ, 2012b, p. 132).

Trocando em miúdos, o movimento formal encontrado no romance - baseado em uma volubilidade na qual há o consumo breve de ideias, convicções, modos literários, posturas, logo desqualificadas e abandonadas por outras - pode ser tomado como a internalização dialética na estrutura artística do movimento próprio da classe dominante brasileira tomada em bloco. Visto que esta absorvia os aspectos culturais relevantes à época e as conquistas civilizacionais, com o intuito de associá-las ao instituto da escravidão, "cujo núcleo de dominação pessoal discricionária contudo zomba da pretensão civilizada (...)” (SchwARZ, 2012c, p. 41). Em suma, é da formação de uma forma dialética adequada à realidade nacional de que se trata. ${ }^{2}$ Assim, o que gostaria de indicar, tal como apontado por Ricupero, é a existência de um processo também de formação, que se completaria na forma, "até porque, como já afirmava o jovem Lukács em trabalho clássico sobre o tema, no momento em que passa a ter forma há a 'conciliação do exterior e do interior”"

2 Para mais sobre a relação entre forma e processo social em Schwarz e Candido, ver Waizbort (2007). 
(RiCUPERO, 2008, p. 64). ${ }^{3}$ Algo próximo, guardadas as devidas proporções, ocorre nas artes plásticas brasileiras, como poderíamos notar a partir das lições de Naves e Souza, as quais serão retomadas abaixo.

Antes, porém, é preciso atentar para o fato de que as determinações 'biográficas' ou 'autobiográficas' serão aqui tomadas na medida em que possam auxiliar no entendimento do processo crítico dos autores em questão, ou seja, não temos aqui a pretensão de esgotar esse campo e muito menos fazer uma sociologia de suas trajetórias intelectuais, assunto demasiado importante, mas que foge de nosso escopo e pretensões.

\section{RODRIGO NAVES E AS ARTES DIFÍCEIS}

Como indica o próprio crítico de artes plásticas Rodrigo Naves, a sua formação nessa seara fora quase que totalmente autodidata, passando a ter uma relação mais estreita e rigorosa com as artes visuais quando de seu encontro com o crítico e artista José Resende e com o crítico Ronaldo Brito (NAVES, 2005; Tognolli e VergueIro, 2012, p. 19-28). Sendo este último decisivo para o caminho que seguiu, pois experiente e possuidor de um rigor que faltava à crítica de artes no Brasil via de regra relegada a escritores e outros intelectuais - além de detentor de uma postura que reivindicava a necessidade do contato com as obras de arte como uma atitude mais decisiva do que conhecimentos livrescos. ${ }^{4}$ Com o passar do tempo, começaram a desenvolver trabalhos em um grupo mais ou menos formal, envolvendo: Rodrigo Naves, Ronaldo Brito, Paulo Venâncio, Paulo Sérgio Duarte, Tunga, Waltércio Caldas, Zé Resende, Sophia Silva Telles e, posteriormente, Alberto Tassinari e Cildo Meireles 5 . Grupo cujo projeto implícito era tentar promover, quanto à compreensão, os trabalhos contemporâneos mais avançados e, ao mesmo tempo, produzir uma nova re-hierarquização e reavalização da arte moderna brasileira, a qual os críticos achavam mal posta (NAvEs, 2005).

3 Veja-se o seguinte trecho: "O destino do crítico é traçado no momento crucial em que as coisas se tornam forma, em que todo sentimento e toda vivência até então aquém e além das formas recebem uma forma, fundem-se e se condensam em forma. Momento místico de união entre o externo e o interno, entre a alma e a forma. (...) A forma é a realidade nos escritos do crítico, é a voz com a qual ele dirige suas perguntas à vida: esse é o verdadeiro e o mais profundo motivo pelo qual a literatura e a arte são os materiais naturalmente típicos do crítico” (LuKÁcs, 2015, p. 40).

4 Um panorama de sua produção crítica pode ser encontrado em Brito (2005).

5 Naves também comenta, em um rodapé, a existência de um círculo de estudos estéticos de nome "Círculo Jabaquara", de que participavam - além de Alberto Tassinari e Sophia Silva Telles, já citados: José Antonio Pasta Jr., Lorenzo Mammì, Nilza Micheletto, Ricardo R. Terra e Sandra Reimão (NAVES, 2011, p. 18). 
Além da influência desse grupo e, posteriormente, das formulações de Schwarz (NAVES, 2009, p. 257) - sobre a relação dialética entre processo social e forma no Brasil (ScHWARZ, 2012a; 2012c) -, três autores estrangeiros foram importantes em sua trajetória, a saber: Giulio Carlo Argan, Lionello Venturi e Clement Greenberg. Neste último, vê-se uma atenção "formalista" maior, no sentido de que deseja fazer uma leitura e interpretação mais exaustivas das obras de arte "em si", sem relacioná-las com outras experiências e com a vida. Em Venturi, seguindo as trilhas de seu pai, Adolfo Venturi, haverá a preocupação de ir além dos estudos um tanto quanto positivistas dos conoscitori italianos, como Morelli e Cavalcaselle, preocupados em seus trabalhos sobre Leonardo, por exemplo, em mostrar uma concepção de Homem que não era mais o protagonista no universo, mas sim um de seus elementos (NAves, 2013, XIII). Já Argan, sem abrir mão de uma análise formal também exaustiva e sofisticada, tenta vincular, de modo mais claro, dialeticamente a experiência artística com outras experiências, aproximando arte e vida (Argan, 1988, p. 13-72; Argan, 2013) (NAVES, 2013, p. XI-XXIV).

Voltando aos objetivos de trabalho do grupo mais ou menos informal de que falava Naves, é preciso enfatizar o ímpeto reinterpretativo da arte moderna no Brasil. Ainda segundo Naves, era preciso repensá-la de maneira que Portinari, Di Cavalcanti e "toda uma tradição populista, meio realista tacanha que dominava a arte brasileira e que de alguma maneira ainda domina" (NAvEs, 2005) - cuja seleção fora feita quase que exclusivamente por literatos, à maneira de Mário de Andrade, Murilo Mendes, Carlos Drummond de Andrade -, desse lugar a outros artistas mais sofisticados, a partir de uma crítica mais rigorosa, como: Oswaldo Goeldi, Mira Schendel, Amilcar de Castro, Alberto da Veiga Guignard, Lasar Segall, Hélio Oiticica, Ligia Clark, Milton Dacosta etc. O referido ímpeto estaria ligado, grosso modo, ao fato de que o segundo grupo de artistas supracitados, ao apostarem em uma arte não figurativa e mais experimental, puderam progredir criticamente quanto às formas e seus desenvolvimento (Adorno, 1970; Adorno, 2011, p. 33-109); explorando de modo mais radical sua lógica interna e seus nexos formais com a vida social, ou, como queria Bürger (2008), com a práxis vital. É claro que não iremos percorrer as análises feitas por Naves sobre esses artistas, contudo é preciso reconhecer que esse esforço de repensar as artes plásticas no Brasil foi um impulso importante para que Naves forjasse uma interpretação de 
maior fôlego sobre a forma difícil da referida arte no Brasil, ${ }^{6}$ algo que passaremos a expor, mesmo que de modo sumário, a partir de agora.

Em seu livro A forma difícil: ensaios sobre arte brasileira (1996), Naves tenta lançar mão de uma interpretação da arte brasileira, mas tal esforço não deve ser indexado à identificação de alguma linha clara que relacionasse produções diversas, constituindo nexos esclarecedores e sim aos óbices de um crítico de arte, o qual acompanhava com muita proximidade e emprenho a arte moderna brasileira. Tudo isso sem sobrepor grandes esquemas teóricos às obras de arte, até porque os raciocínios ali presentes nasceram de um constante corpo a corpo com os trabalhos analisados, sendo que o esforço de sistematização de nosso crítico poderia decorrer da indispensabilidade de se estabelecer relações e correspondências, as quais possam melhorar a compreensão e ampliar o significado da produção artística nacional, livrando os críticos de uma proximidade por vezes imediatista e sufocante.

É claro que a análise enfrentou problemas de sistematicidade e de certa maneira de tradição, já que até pelo menos 1970, excetuando-se o período do barroco mineiro, a produção em artes fora extremamente esparsa e irregular, dificultando a constituição de um meio mais rigoroso e complexificado, contribuindo para gerar um sentimento de incerteza naqueles que trabalham nas/ a partir das artes plásticas. Comparando com a literatura, o cinema, a arquitetura e a música, sua capilaridade social e organização interna são sensivelmente mais frágeis, podendo mesmo gerar casos de insensatez individual, os quais cometeriam a heresia de colocar em xeque publicamente artistas como Mira Schendel e Segall, comportamento impensável com um Machado de Assis ou mesmo com Glauber Rocha. É evidente que isso não é desculpa para o desconhecimento que cerca as artes, detentor lá de suas raízes históricas, como a ojeriza portuguesa ao trabalho manual e também o fato de as periodizações até ali feitas no Brasil não terem sido rigorosas o suficiente para dar conta de uma situação histórica e produção tão especificas, mostrando seus maiores limites numa época em que as obras e trabalhos passam a aumentar rapidamente.

Estas dificuldades acabam, ao fim e ao cabo, obrigando o autor, ao longo de sua atividade intelectual, a manter certa proximidade com as obras, o que traria suas

6 Nesse momento é importante lembrar o comentário certeiro de Mammì: "A ideia de forma difícil, de fato, não é algo que possa ser expandido com facilidade; não é um conceito nem uma poética, mas um diferencial, um resíduo que distingue muitas das obras produzidas no Brasil de suas parentes europeia e norte-americana. Reconhece-se mais facilmente numa linha ou numa cor que na descrição de uma escola, de uma tendência ou de uma época. É uma escolha interpretativa preciosa, ao falar de uma arte como a brasileira, para a qual a classificação em escolas e tendências soa quase sempre rígida e exageradamente determinada” (MАммì, 2012, p. 298). 
vantagens. Visto que fora esse corpo a corpo sistemático que fizera o crítico chegar à constatação de que os trabalhos artísticos brasileiros eram portadores de uma obstinada timidez formal, enquanto toda produção moderna internacional havia se caracterizado "por uma aparência forte, devida sobretudo a uma significativa redução da natureza representativa de seus elementos" (NAvES, 2011, p. 19). Na Europa e em seu experimentalismo modernista, viam-se linhas, cores, superfícies, tudo referente às artes com um novo estatuto e com uma intensidade até então inauditas, algo completamente diverso do que ocorria no Brasil, já que boa parte dos trabalhos por aqui realizados incorporam as mudanças modernas, porém de um modo particular. As obras são envolvidas por um tipo de morosidade perceptiva que reduz a sua força de aparecimento; cores e formas passam a ganhar certa autonomia e já não mais se escondem atrás dos seres figurados. Uma independência que leva a um jogo peculiar, em que as formas, por exemplo, passam a se ocupar delas mesmas e sua definição mais clara fica na indeterminação. Nesse cismar constante, poder-se-ia sugerir uma preocupação modernista com o processo de gênese formal, todavia este movimento não se cumpre e a afirmação de formas e cores assenta-se na suspenção de sua atualidade; ao modo de Tarsila do Amaral, por exemplo, a qual acaba por comprometer seu tonalismo sútil com a constituição de imagens estranhas e primitivas, como pode ser visto em seu quadro Urutu de 1928.

Contudo, é preciso notar que a particularidade e estranheza nas artes por aqui feitas, devem, no final das contas, ser tratadas de modo muito familiar no Brasil, visto ser este também um país demasiado particular. Particularidade advinda de sua formação histórica ser bastante singular e constitutiva de uma vida mental pautada em uma verdadeira dialética do localismo e do cosmopolitismo (CANDIDO, 2011b, p. 117), levando ao impasse de, a um só tempo, sermos desajustados frente à categorização à europeia e ao fato de esta nos ligar à modernidade. Sendo possível ver em algumas de nossas mais refinadas manifestações artísticas isto: em Ismail Nery, cujos quadros têm como movimento a queda, em uma espécie de sedimentação mansa e reconfortante, desdizendo alguns pressupostos do cubismo; Anita Malfatti, com temas que se pretendem expressionistas, mas que acabam sendo representados de modo mais ou menos expressionistas, possuidora de uma gestualidade marcada e contornos deformados com certa padronização; Milton Dacosta, apesar de admirável, inverte Modrian e seu construtivismo claro, criando estruturas que a todo momento ameaçam ceder ou mesmo em Hélio Oiticica e Lygia Clark, artistas dos mais radicais, que ao tentar identificar arte e existência - com o fito de problematizar/acabar com uma contemplação tradicional - acabam por identificar vida e proteção, em uma interioridade problemática portadora de uma 
dilaceração que os acossa por todos os lados. Ou seja, identificar-se-ia uma dificuldade de forma que perpassa uma fatia considerável da melhor arte nacional, com uma relutância em deixar os trabalhos fortemente estruturados e, assim, colocá-los em uma relação mais positiva e conflituosa com o mundo, levando-os a um retraimento estranho ao caráter prospectivo de boa parte da arte moderna. Porém, esse movimento retraído não os livra da realidade, fortemente presente nas feições primitivas das obras de Guignard e Volpi, pois, a partir de sua timidez, esses trabalhos supõem um modelar suave do mundo, próximo ao artesanato moroso e não ao trabalho industrial, marcando uma recusa à sociedade violenta do trabalho. Todavia, esse ideal meigo ali defendido conspira contra as suas expectativas, dado que "essas aparências amenas e essas formas frágeis não podem se opor à pressão do real, que os coage sem cessar" (NAVEs, 2011, p. 27).

E aqui o passo teórico essencial ao nosso argumento, já que há a ligação da forma a outras experiências, sendo possível identificar a origem dessa formalização difícil à existência de amplos setores da população em atividades não tipicamente capitalistas. Assim, a forma pouco institucionalizada e estruturada da sociedade brasileira que "certamente estimula e dá veracidade às formalizações que resistem a uma determinação mais acentuada. Mas não deixa de ser intrigante o investimento afetivo despertado por essas formas residuais de convivência” (NAves, 2011, p. 27). Naves confessa mesmo admirar homens e mulheres tão sensíveis, os quais, contudo, deixam de lado a vinculação desses setores menos organizados da sociedade e sua vinculação com o sistema econômico mundial, não traduzindo em violência, desespero e dor "a extinção necessária e iminente desse mundo que lhes serve de modelo" (NAvEs, 2011, p. 27).

Uma doçura, contenção e equilíbrio derivados da esperança de resgatar artisticamente a experiência de certos setores da população, um ideal tão singelo que poria em xeque formas mais afirmativas de se fazer arte. Experiência social tão profunda que encontra ressonância até num radical como Oiticica, porque na ausência de uma força social unificada que fizesse surgir novas possibilidades, a única possibilidade aparente passa a ser essa utopia de rememoração, docemente anticapitalista, todavia fornecedora privilegiada de indícios reais de uma sociabilidade outra e não vinculada às reviravoltas e desmedidas do Capital. Essa mesma indecisão social que alimenta essa timidez, também proporciona uma tendência contrária, em que o "travo que caracteriza essa dinâmica social descompensada é incorporado formalmente em algumas obras, que revelam em sua estrutura o movimento dúbio e arrastado de uma sociedade atravessada por descompassos e ambiguidades" (NAvEs, 2011, p. 29). Formalização encontrada no expressionismo 
de um Iberê Camargo, em que evidencia-se uma atração pelo lado opaco da vida, cujas formas fortes, contudo estáveis, "afastam a afirmação de um sujeito determinado e desfavorecido em seus desígnios." Gerador de obras com intensidade inédita, mas que resistem a entregar as formas aos seus limites, sobressaindo-se daí "uma forma difícil, e não mais aquela relutância formal" (NAVEs, 2011, p. 29). Em resumo, um passo qualitativamente a frente da supracitada relutância presente em nossas obras anteriores.

Com suas especificidades, outros e outras artistas indicam a mesma questão: Goeldi, com o sofrimento de seus personagens, decorrente de uma singularidade miserável; Eduardo Sued, quando reúne intensidade e dispersão; Sérgio Camargo, radicalizando a tensão entre unidade e fragmentação; Mira Schendel, cuja intensidade é revelada em seus traços acossados por uma descontinuidade iminente, pronta a destruir a completude do gesto, em que cada avanço forja realidades específicas e densas; além do confronto tenso entre o ferro espeço e o rigor formal, constituidor de uma indeterminação que é força em Amilcar de Castro. Características formais, possuidoras de um forte potencial crítico, dado que por meio dessa forma difícil, "experimentamos uma realidade travada, muito mais próxima das crises e dos impasses desencadeados pelo desenvolvimento tecnológico do que da maleabilidade que ele introduz em seu manejo da natureza e dos demais processos" (NAVES, 2011, p. 38). Para melhor aquilatar essa relação entre processo social e forma em Naves, passo agora por uma breve incursão sobre seu texto a respeito de Jean-Baptiste Debret - um estrangeiro nada espontâneo - e suas aventuras e percalços em forjar uma forma que dê conta de um tipo de existência diversa da França revolucionária. Lembrando que o referido francês era discípulo de Jacques-Louis David, o qual desenvolvera um estilo neoclássico de certa forma bem fundado nos pressupostos sociais da sociedade francesa revolucionária (ARGAN, 2010, p. 244-253).

Nesse bojo, confrontamo-nos com uma disjunção saborosa entre título, forma e processo social, encontrada na aquarela Le premier élan de la vertu guerrière (1827), uma das primeiras pinturas feitas pelo artista francês. O título colocado remeteria diretamente às principais características do neoclassicismo, liderado por David e os ideais da Revolução Francesa, mas na aquarela vê-se quase seu oposto. O elogio da virtude teria como objetivo marcar a identidade entre a disposição para o bem e a defesa do interesse comum e da igualdade, apresentando-se não com uma conotação contemplativa e sim como atividade, visto que é qualificada como guerreira. Caráter ativo acentuado pelo ímpeto que a envolve, como se estivéssemos diante de um elã irresistível. $\mathrm{E}$ o fato de ser um primeiro impulso aponta 
a possibilidade de aperfeiçoamento desse campo do espírito, apontando vínculos essenciais com o Iluminismo.

Na pintura, mais precisamente em sua forma, essa virtuosidade deveria se mostrar como uma forma ideal, a qual deveria submeter todo o sensível ao seu ímpeto, até porque uma ordenação unívoca e firme indicaria uma vontade reta, sem ambiguidades e longe da sensualidade. Esse movimento seria completado com a utilização de uma temática edificante, à maneira dos feitos espartanos, da República romana, Leônidas, Brutus, etc. Tudo muito bem colocado teoricamente, porém em um corpo a corpo com a aquarela vê-se quase seu contrário: uma turma de meninos (brancos e negros) pobres tenta reproduzir uma parada militar, localizada mais ao fundo, talvez querendo indicar que a virtude francesa ainda alcançaria o infante povo brasileiro. Mas a pintura não diz o mesmo, visto que indica o brutal afastamento com relação ao padrão francês do que um futuro edificante na colônia, chamando a atenção a ausência completa de uma linha de força que dê ao desenho direção e movimento. A fila no primeiro plano, um tanto quanto desordenada, forma uma diagonal muito leve, quase paralela à linha de base. Todo o quadro, desde a sua disposição da esquerda para direita até a disposição dos garotos, indica, ao fim e ao cabo, a dissolução de contornos e a redução de sua força.

Em suma, o ideário neoclássico não teria cabimento algum por essas terras, dado que o afastamento da natureza era por demais limitado e o discurso do dever encontrava toda sorte de embaraços, de sorte que no Brasil seria preciso encontrar uma forma que revelasse com maior verossimilhança sua realidade, diversa da França revolucionária, portanto distante dos pressupostos neoclássicos. Preocupação que transparecia em Debret e suas pinceladas, produtoras de aquarelas que incorporavam formalmente uma dinâmica social típica do Rio de Janeiro e do Brasil, proporcionando, com essa mudança formal de seu trabalho, não só ganhos artísticos muito importantes, mas uma melhor compreensão da vida na colônia.

Retomando o nó histórico, a feição rudimentar do Rio de Janeiro, com uma vastidão de escravos, homens livres e pobres, sem 'urbanização' alguma e uma monarquia 'exilada', inviabilizava qualquer pretensão de aclimatar, com sucesso, o neoclassicismo por essas terras; lembrando que este movimento defendia uma arte em que a vontade dobrasse e conduzisse a natureza humana e não-humana, de forma que a cidade seria, por excelência, seu domínio, mesmo que apareça sob a forma idealizada de episódios passados modelares. Em síntese, a arte aparecia como guia da vida urbana. Todavia, a existência da escravidão no Brasil impedia qualquer tentativa de transpor a forma neoclássica para cá de modo satisfatório e com verdade; nesse bojo, é importante notar que Debret teve um papel importante 
ao destacar essas formas fora de lugar - segundo as lições de Schwarz (2012a; 2012c). Até porque, na França "um violento enfrentamento social fez o Terceiro Estado encontrar no passado greco-romano um modelo ético de comportamento que o colocava como herdeiro (...) de uma importante tradição republicana e igualitária” (NAVEs, 2011, p. 78). As concepções de virtude e heroísmo encontravam sentido histórico com aquele movimento revolucionário cujo objetivo era regenerar toda a sociedade francesa, de sorte que nas artes esse universalismo demandava formas idealizantes adequadas aos modelos, entretanto a configuração da estrutura social brasileira e suas especificidades não oferecia uma boa base a esse formalismo moralizador neoclássico.

Voltando às aquarelas de Debret, marcadas pela fragmentação, fragilidade, ambiguidade de forma e uma pressão que sofrem do espaço, cujo efeito apreende muito mais do que se passa no país, ao mesmo tempo em que testemunham um espírito conciliador que não vê a possibilidade de diferenciação na sociedade brasileira. Apresentando-se como uma experiência indelével nas artes brasileiras, dado que essa dificuldade de estruturação das obras tem por trás uma realidade bastante dissolvente e impositiva, demonstrando uma visão artística limitada - até para o Brasil do XIX. Contudo, essa dificuldade apresenta-se em boa parte da melhor arte nacional, de uma maneira que a compreensão das artes de Debret afigura-se como um passo importante para entender-se as nossas especificidades estéticas; este, como neoclássico menor, abriu-se às idiossincrasias de nossa realidade e sua dificuldade de representação, fazendo com isso não uma grande obra, mas sim algo que nos pertence, a primeira grande experiência de nossos dilemas nas artes plásticas.

Portanto, a má formação brasileira também teria sua formalização nessa forma difícil de que fala Naves, uma formação que também se constitui na forma, ao modo do que Schwarz já havia sugerido quanto ao segundo Machado e seus romances maduros, bem como nas reflexões de Ricupero sobre o tema. Partiremos agora para algumas considerações sobre Gilda de Mello e Souza e seus ensaios sobre artes plásticas no Brasil, tentando, de um modo ou de outro, trazer à baila o fio da formação em meio à suas linhas.

\section{GILDA DE MELLO E SOUZA: ENTRE NOTAÇÃO EUROPEIA E EXPERIÊNCIA BRASILEIRA}

À primeira vista, a crítica Gilda de Mello e $\operatorname{Souza}^{7}$ e seus ensaios apareceriam como opostos aos esforços interpretativos e críticos de Naves, principalmente se

7 Com a breve incursão sobre algumas influências decisivas para a nossa ensaísta não se pretende de modo algum esgotá-las, ou mesmo apresentar uma trajetória intelectual e institucional consistente, porém algumas indicações de ordem bibliográfica se fazem necessárias. Quando a autora, 
o critério para tal comparação fossem seus referenciais teóricos. Este contando com autores de certa tradição "materialista" - devedora de uma visão que relacionava, de modo complexo, deixe-se claro, experiência material e experiência formal/ artística - e aquela com autores que, para seguir o jargão - muitas vezes apressado e enganoso - vinculados à uma visão formalista das artes, na qual as formas ficariam ensimesmadas e se assentariam em abstrações auto-referenciadas, ao modo de um Prometeu acorrentado.

Nesta última contaríamos com os mestres da escola de Warburg, tão heterogêneos entre si, como Aby Warburg e sua iconologia - preocupada com a psicologia das imagens e as formas assumidas, ao longo do tempo, por estas e as razões de suas transformações; ou como Erwin Panofsky e Ernest Gombrich, inquietados com a decifração rigorosa e erudita de significados dos conteúdos das imagens, baseados em uma análise progressivamente aprofundada, em meio a passagens das instâncias as quais iam do objeto de intepretação, passavam pela fonte subjetiva desta, até chegar ao seu chamado corretivo objetivo. Sendo assim, atravessavam constantemente a iconografia em direção à iconologia, em um movimento que beirava a circularidade, mas que nem por isso deixava de ser rigoroso (PRADO JR., 2007, p. 15). Nesta empreitada acabavam por lançarem mão de um conceito de representação, construído "a partir de uma relação de imagens com outras imagens", em que, "a passagem de uma imagem para outra se faz pela mediação de uma ideia, de uma 'imagem mental" (Menezes, 2003, p. 91) e não da "realidade". Nesse bojo, não poderíamos esquecer também do quanto Souza elogiava o método indiciário próprio dos chamados connaisseurs, tão bem plasmado pelo médico e artista italiano oitocentista Giovanni Morelli, principalmente em seus trabalhos de esquadrinhamento de diferentes estilos artísticos pelas vias do detalhe (ARANTES, 2006, p. 311).

Os pontos anteriores parecem ganhar força a partir dos próprios ensaios e comentários da autora, como fica patente na segunda nota de seu famoso ensaio "Pintura brasileira contemporânea: precursores", em que, fiando-se e glosando os ensinamentos de Gombrich em seu Arte e Ilusão, ${ }^{8}$ Souza argumenta que o ato de

contando com 31 anos, terminou seu doutorado intitulado A moda no século XIX - doravante $O$ espirito das roupas (SouzA, 2001) - o trabalho pioneiro e criterioso não fora bem recebido por seus pares na antiga FFCL-USP. Dominada, à época, por um espírito um tanto quanto cientificista e pouco afeito ao ensaismo e seu linguajar próprio. Além de ser pouco lembrada por sua coragem institucional, a qual, a duras penas, garantia a autonomia do Departamento de Filosofia, frente ao regime militar e seus asseclas encalacrados na burocracia e direção universitárias. Para mais ver Souza (2004, p. 61-77); Pontes (2009, p. 269-310); Galvão (2007, p. 51-71); Chauí (2007, p. 23-51).

8 Ver, principalmente Gombrich (1983, p. 27-83). 
ver jamais é inocente, até porque, diferentemente do que John Ruskin e os impressionistas acreditavam, seria sempre um ato de aprendizado, por meio do qual estabelece-se menos uma relação com a natureza do que com esquemas perceptivos anteriores. Logo, mesmo "na arte chamada naturalista o artista não traspõe para a tela o resultado neutro e objetivo de sua análise do mundo exterior, mas aplica à análise do real os esquemas perceptivos que herdou da tradição" (SouzA, 2008, p. 274). Ou, quando imbuída de um espírito indiciário sem igual, presta atenção a pontos sumamente ignorados pela crítica brasileira de artes anterior a ela, à maneira da postura e das técnicas do corpo do caipira nos quadros de Almeida Júnior ou da simbologia das mãos e braços nos quadros da série Cenas da vida brasileira, 1930/1954, de João Câmara Filho (SouZA, 2005, p. 113 - 125).

No entanto, com o quadro até aqui conformado, como é possível que a autora tenha conseguido, como indicava o começo do trabalho, expor as linhas evolutivas da experiência nacional transfigurada em forma pelas artes plásticas? Antes que indiquemos as raias do paradoxo como destino destas reflexões, convém procurar algumas pistas nos textos de Otília e Paulo Arantes, bem como nos ensaios de Souza sobre esta seara. Segundo Otília Arantes, no vai e vem entre realidade, história e pintura, em que nossa autora se move, esta utiliza permanentemente e ao mesmo tempo relativiza as lições dos mestres anteriormente apresentados (ARANTES, 2006, p. 315). O ato de relativização levado a cabo por ela fora de suma importância para o quadro crítico nacional e entroncava diretamente na tradição intelectual modernista e nos trabalhos do grupo Clima, por duas razões: i) havíamos dito anteriormente que na feitura das artes, olhar-se-ia a partir de esquemas estéticos já previamente desenvolvidos e herdados, porém quando os esquemas visuais eram advindos da Europa e topavam com os dados 'imediatos' de nossa bruta realidade nacional, necessariamente precisaria ir para além dos ensinamentos de Warburg e seguidores - ponto melhor concrescido com a exposição posterior; ii) seguindo o espirito do grupo Clima ${ }^{9}$ (Pontes, 2008; Arantes, 1974, p. 78) e de intelectuais modernistas, à maneira de Mário de Andrade, não faria sentido manter impunemente a orientação "imanentista” de Gombrich, visto que o que galvanizara seus esforços era um tentativa de "detectar os lineamentos da formação de uma arte brasileira" (ARANTES, 2006, p. 320), voltando-se, pela via da paixão pelo concreto (SouZA, 2008, p. 261), ${ }^{10}$ para o que não era consagrado, para os artistas menores

9 Para um belo retrato de grupo, ver Pontes (1998).

10 O ensaio de Gilda sobre a perícia e a concreção do crítico Paulo Emílio Salles Gomes pode muito bem ser reaproveitado para apreciação dos trabalhos da autora - como para todo o grupo Clima, baseados em uma atitude crítica que privilegiava o corpo a corpo com as obras e que conscien- 
e examinado o nosso acanhado meio artístico brasileiro, sem aplicar ou impor grandes temas e teorias em voga na cena internacional à nossa realidade especifica.

Voltando-se mais detidamente para os ensaios da crítica sobre a pintura brasileira moderna e o vanguardismo do mesmo período, é interessante notar que as análises e considerações sobre Almeida Júnior não eram em si novas, contando com as companhias do jovem e passadista Oswald de Andrade, defensor de uma arte nacional, considerando nosso pintor um precursor desta; de Monteiro Lobato, propugnador, ao mesmo tempo, de críticas cujo objetivo era desmoralizar o expressionismo de Anita Malfatti e elevar Júnior à personagem inauguradora da pintura nacional; ou mesmo de Mário de Andrade, defensor animado do "moderno", et pour cause, contrário àquelas figurações plásticas (ARANTEs e ARANTES, 1997b, p. 71). Souza, porém, seguiu um caminho diferente, visto que ao não sentir a necessidade de prestar contas a um passado incerto e ao se ver livre das amarras do programa nacionalista, não precisou engessar sua liberdade criadora e crítica em prol de um corpo definido de ideias (SouzA, 2008, p. 319). ${ }^{11}$

De todo modo, ao começar seus ensaios sobre os precursores da arte contemporânea brasileira, a autora elogia a iniciativa do Museu Lasar Segall, cuja exposição reunia artista como Belmiro de Almeida, Visconti e Timóteo da Costa, atuantes no mesmo momento da exposição de Malfatti - anteriores ao momento da virada modernista ${ }^{12}$ - sugerindo aos visitantes que a olhassem tendo em vista essa passagem/ reformulação das artes plásticas, vislumbrando ali certos traços do futuro. Entretanto, sugere que deveríamos girar a roda histórica um pouco mais para trás e estudar com atenção artistas pretéritos, como Almeida Júnior e Jorge Grimm, um tanto quanto acadêmicos, entretanto portadores de elementos inovadores em seu tempo. Concentrando-se principalmente no primeiro, nossa autora argumenta que fora ele quem auxiliara na supressão da monumentalidade de nossas obras, na renovação de assuntos e personagens e na vinculação orgânica das figuras ao seu ambiente e, quiçá, na revisão no tratamento da luz. Desta

temente deixava de lado os infindáveis debates teóricos movidos ao sabor das academias do centro capitalista (SouzA, 2008, p. 259-273).

11 Nacionalismo que considerava ser, a um só tempo, uma força produtiva e uma constrição: "No entanto, aceito como a melhor solução, o Nacionalismo não era isento de tensões e podia ter um efeito duplo, pois se de um lado ordenava o período, favorecendo a superação das vanguardas, de outro, à medida que era um corpo definido de ideias com finalidade normativa, cerceava fatalmente a liberdade criadora" (SouzA, 2008, p. 319). Por superação das vanguardas é preciso entender que a rápida troca de um programa estético europeu, por outro nacional "teve a vantagem de evitar o prolongamento da etapa destrutiva, que na Europa se expressou sobretudo pelo Dadaísmo e o Surrealismo, e que teve conotação fortemente individualista" (SouzA, 2008, p. 319).

12 Para mais sobre o período ver Amaral (2010) e Batista (2012). 
feita, é "com ele que ingressa pela primeira vez na pintura o homem brasileiro" (SouZA, 2008, p. 274, grifos colocados). Na figura do caipira paulista mais especificamente. Porém, o seu mérito essencial não foi ter simplesmente pintado o dito cujo, até porque teria se transformado em mais uma das figuras tradicionais e descompassadas de arte, à moda dos índios, dos negros e Iracemas em postura de ninfas, na pena de nossos cronistas, viajantes e pintores antigos. Coube ao nosso pintor revelar, pelas vias de seu regionalismo, a verdade profunda dessa personagem nacional e com escrúpulos de etnólogo - a seguir veremos que o ponto é mais profundo - conseguiu figurar "não apenas a aparência externa, os traços do rosto ou a maneira peculiar de se vestir, mas a dinâmica dos gestos - aquilo que Marcel Mauss descreveu com tanta perspicácia num ensaio célebre, designado como técnicas do corpo" (SouzA, 2008, p. 275).

Essa acuidade observacional já havia transparecido em um quadro como $O$ derrubador (1879), pintado ainda em Paris, mas que trai as convenções realistas na pintura do rochedo e que em outros elementos traz a nostalgia de sua distante pátria; nesta obra fica patente, como queria Souza, que é nosso "o jeito do homem se apoiar no instrumento, sentar-se, segurar o cigarro entre os dedos, manifestar no corpo largado a impressão de força cansada" (SouzA, 2008, p. 276). Um lineamento que o pintor aprofundará em obras posteriores, ao modo de $O$ violeiro (1889) e Amolação interrompida (1894), conseguindo cada vez mais afinar sua análise sobre o comportamento corporal do homem do campo, apreendendo "à sua maneira canhestra de caminhar, sem nobreza, mantendo os joelhos meio dobrados enquanto apoia os pés no chão" (SouzA, 2008, p. 276). Um empreendimento sem dimensionamento correto e sem precursores, algo impressionante, visto que conseguiu trazer para as telas a notação do gesto, "lutando contra as reminiscências artísticas, que lhe impunham, a cada momento, a postura europeia civilizada - nos painéis sacros, nos históricos, nos quadros de gênero, nas composições alegóricas como nas realistas, na representação do povo como na das classes altas" (SouzA, 2008, p. 278). Trata-se de um modo inédito de notação visual, a partir do qual tornou-se possível descobrir e sondar a verdade íntima dessa personagem central. Procedimento contrário ao de um Hans Staden ou a um Jean de Léry, pois ao tentarem representar indígenas tais quais eram, acabam por transpor esquemas emprestados do maneirista italiano Baccio Bandinelli, por exemplo.

Sem embargo, dando um passo atrás e esperando dar dois à frente, como a nossa crítica conseguiu ver isto? Segundo o argumento de Otília e Paulo Arantes, além das providências educativas de uma formação artística e moderna ímpar e da prática voltada ao detalhe e o corpo a corpo com o estudado - ponto comum nos 
participantes do grupo Clima -, Souza tinha em si uma empatia pelo "caipirismo imanente" de Júnior, pois viveu boa parte de sua infância na fazenda do interior paulista. Algo que poderia ter um caráter anedótico, mas que, ao fim e ao cabo, ganha consistência metódica - e de filtro intelectual do vivido, diga-se - quando nos lembramos do tipo de intelectual gestado naquele período, entre as décadas de 1930 e 1940, impulsionado por uma visão não aristocrática de mundo encarnada nos estudos feitos sobre populações pobres e a cultura rústica (ArANTES e ArANTES, 1997b, p. 87-88; p. 95-100; CANDido, 2011a, p. 229-243). Por essa época, Souza e seus parceiros de geração passaram a organizar suas ideias e um modo de pensar sobre o Brasil, voltado "para as regiões mais tangíveis da experiência brasileira sedimentada de preferência nas obras de arte" (Arantes e Arantes, 1997b, p. 96). Experiência da "diferença brasileira", é claro, ou melhor, da diferença entre nossa realidade periférica e a norma europeia para cá transposta, em um movimento de alta voltagem e propiciador de um curto-circuito, do qual não sairiam ilesos tanto um localismo vulgar, quanto um cosmopolitismo abstrato - extremos do movimento de báscula, velho conhecido da vida do espirito dos intelectuais periféricos (ARANTES, 1992).

Fazendo sistema com esse mundo das formas frequentado por Souza, informantes privilegiadas de nossa experiência diferencial, há que fazer referência também ao estudo $O$ espirito das roupas, dado que lá ao ligar a moda com a chamada estrutura social, não deixa de reparar que aquela consiste em uma arte situada estrategicamente entre as chamadas artes menores, como a dança, e as maiores, à maneira da arquitetura e das artes plásticas. Situada assim, no mundo supracitado, porém de uma maneira específica, porquanto sua essência embasava-se na conquista do espaço pelo movimento, fazendo-a rítmica, sobretudo. $\mathrm{Ou}$ melhor, uma arte de compromisso, posto que o traje inexiste sem o movimento e a dinâmica dos gestos, efetuando novos equilíbrios e figurações (SouzA, 2001, p. 41). Destarte, ao depender da medida e desmedida da gestualidade, a moda afigura-se como a mais socializada dentre as artes, um dos elementos "que talvez tenham contribuído mais de perto para a cristalização da sensação plástica de que o essencial do 'homem brasileiro' deveria ser procurado no seu movimento corporal" (Arantes e Arantes, 1997b, p. 90). Após esta pequena digressão, voltemos a Grimm e outras manifestação de um horizonte artístico outro.

Num outro capítulo controverso dos nossos precursores, Souza elenca o pintor alemão Jorge Grimm e a doutrinação do crítico Gonzaga Duque, operadores tanto de uma transposição da estética do ar livre por essas bandas, quanto do clareamento das paletas de cores. Tudo isso baseado em esquemas europeus 
- difundidos pelos pintores da Escola de Barbizon e pré-sistematização e radicalização impressionista, aqui aclimatados como podiam e marcadores de uma nova relação do artista com o ambiente. De sorte que a insinuação da invenção de uma luz brasileira devido à observação de nosso "ambiente colorido e tropical" carece de maior fundamentação (SouzA, 2008, p. 281-282). Nada de novo para aqueles acostumados com as reviravoltas da experiência nacional e seus percalços de articulação entre vida mental "sob constante ameaça de estar se engajando em uma pista inexistente e o panorama social próximo, cuja inconsistente razão de ser raramente favorece a dita articulação, cujo modelo de consistência sabidamente se encontra na Europa" (Arantes e ArANTES, 1997b, p. 74).

Percalços, reviravoltas e redescobrimentos encontrados em outros momentos de nossa arte nacional, à maneira da analogia que poderia ser feita entre a viagem de Mário de Andrade à Amazônia e seus comentários sobre a obra do jovem pernambucano Cícero Dias. Animados por um projeto de redescobrir o Brasil real, visto ao vivo, agitador de qualquer espírito intelectualizado e europeizado do Sul, o qual poderia ser encarado como um de nossos episódios de transplantação brasileira da estética do ar livre (SouzA, 2005, p. 49-73). Tratando-se de um caso clássico de invenção do país por meio da imaginação, via passagem do país de ateliê para o país "real", transcorrido numa viagem de descoberta e preparador de uma apropriação letrada do motivo nacional; reproduzindo o conflito já exposto anteriormente entre "sentimento da paisagem atrelado ao país carecido de ser descoberto atrás das florestas; imaginação artística armada noutras bandas menos incivis" (SouzA, 1997b, p. 77-78). Ou na relação, às vezes difícil e às vezes acertada, entre artistas modernistas e o projeto nacionalista das artes, tão bem expresso nas afinidades eletivas do expressionismo advogado, posteriormente, por Mário de Andrade e a volta à realidade nacional: aquele queria destruir o homem clássico e este visava a destruir a europeização do brasileiro, com o intuito de "desentranhar os traços inconscientes e fatais da nacionalidade” (SouzA, 2008, p. 318).

Desentranhamento muito bem-sucedido nas carreiras de um Di Cavalcanti e de uma Tarsila do Amaral, notadamente a última, pois ao jogar sua arte numa conjunção difícil, em que tentaria "ver a realidade primitiva e desordenada do país através de um crivo europeu, altamente racional” (SouzA, 2008, p. 329), conseguiu colocar na ordem do dia uma síntese entre a estética nacionalista, em seu apogeu nos anos de 1920-1930, e os aprendizados cubistas recentes na Europa; principalmente em sua fase Pau-Brasil, marcada pela viagem que fez ao interior de Minas com os modernistas e Blaise Cendrars. Tanto é que substitui os esquemas colorísticos de seu mestre Fernand Léger "por outro mais ingênuo, baseado na 
observação da cultura local, exagerando os acordes verde-amarelos e explorando as tonalidades das casas coloniais, dos bauzinhos de folhas de flandres" (SouZA, 2008, p. 329). Contudo, a síntese até aqui apresentada, de uma forma ou de outra, também vinculava-se à nossa experiência diferencial, camuflada na junção entre cubismo e mata, até porque para Tarsila e Di Cavalcanti o nacionalismo apresentou-se como uma solução pertinente a que aderiram quase que naturalmente, entretanto "a obra que realizaram não revela afastamento apreciável da Europa; trai a filiação muito próxima dos mestres europeus e mesmo certos esquemas artísticos eruditos, camuflados sob a aparência selvagem dos temas" (SouzA, 2008, p. 344).

Depois de tudo o que fora exposto, que fio condutor seria possível destrinchar desta linha que passa do nosso caipira tornado figura e não apenas fundo, até certo brutalismo presente em um Abaporu (1928) e Antropofagia (1929) - todos apresentados sob o signo do descobrimento ou do redescobrimento do Brasil? Talvez, como sugerem Otília e Paulo Arantes, a estruturação interna da formação da pintura nacional estaria nos percalços, desdobramentos e resoluções dessa dissonância quase que permanente entre notação europeia e realidade brasileira, ou, nas palavras dos autores:

Se assim é, acrescentamos que a tarefa sublinhada linhas acima de vincular organicamente as figuras ao ambiente também pode ser entendida como a transposição plástica, ou o exato equivalente pictural, do problema crucial a que se resume a instabilidade básica definidora de nossa experiência, no caso, intelectualmente filtrada pela organização das formas. E, se isso for verdade, poderíamos igualmente acrescentar, sem muito medo de errar, que nessa comunicação tácita entre as duas esferas reside o real assunto de meditação de Dona Gilda sobre as idas e vindas da pintura brasileira (em formação?). Ora, se tudo isso é mesmo fato, a tal dificuldade com cara de solução se concentra por assim dizer na dupla fidelidade (outra dimensão - chave da experiência intelectual de todo brasileiro que não queria se deixar ofuscar por miragens) que se pode reconhecer no seguinte entrecruzamento: de um lado, a figura, o 'homem brasileiro', o novo personagem no qual se encarna a verdade de nossa gente, que justamente estreia na marcha lenta da pintura local pelas mãos de Almeida Júnior, porém abafando reminiscências herdadas, no caso, de sistematização europeia das soluções acadêmicas; de outro, do lado do(s) fundo(s), a 'construção da paisagem' por um olhar instruído por essa mesma herança cultural. Num caso, identificação de fundo na esteira de uma visão educada à sombra da norma culta; no outro, revelação inaugural da figura na sua verdade pela inocência de que só um olhar 
desarmado é capaz. Quem sabe se a mola propulsora da formação da pintura brasileira não se encontraria nos múltiplos desenvolvimentos, ou resoluções, dessa dissonância (ARANTES E ARANTES, 1997b, p. 74 - 75, grifos colocados).

Nesse ínterim, pode-se ver que Souza, em seu conjunto de ensaios sobre artes plásticas, conseguiu enxergar e escandir no mundo das formas (LuKács, 2015, p. 40) a nossa experiência nacional, entre a fidelidade às ideias e esquemas conceituais europeus e à realidade brasileira. No entanto, é preciso deixar claro que a formação de que nos fala não é nada fácil, permeada por uma série de percalços e desenvolvimentos vários; uma formação difícil, em resumo. Tendo isso em mente, passaremos agora para algumas breves colocações sobre as diferenças e similitudes entre Naves e Souza.

\section{CONSIDERAÇÕES FINAIS: 0 MUNDO DAS FORMAS PELO CRIVO DE NAVES E SOUZA}

Tendo em vista o que foi dito anteriormente, é importante salientar, pelo menos, duas distinções entre Naves e Souza: i) as influências teórico-metodológicas de que partem são, em boa medida, diferentes; ii) as referências de artistas e obras de arte de que partem também divergem, levando mesmo a certa discrepância quanto ao tempo transcorrido entre Debret e as obras dos precursores primeiros do modernismo brasileiro, por exemplo. À primeira vista, necessariamente, levariam a teorizações sem um fio de ligação possível; todavia é preciso que tenhamos em mente uma aproximação importante entre os dois: ambos, no final das contas, possuem uma postura crítica assaz assentada no contato sistemático e direto com as obras de arte, fazendo com que não deixem de lado a análise material e imanente de seus objetos de pesquisa em prol de uma teorização externa e sem cabimento quanto ao objeto de estudo - algo comum no grupo Clima, de Souza e no grupo de Naves, composto por um Ronaldo Brito e um José Resende, participes e entusiastas desta forma de análise.

À vista disto e do que foi até aqui sedimentado, é possível entender como Souza - atentando para os percalços, desdobramentos e resolução da dissonância entre notação europeia e a realidade brasileira, fundamental para a estruturação interna da formação da pintura brasileira - e Naves - com sua escolha interpretativa, na qual a forma difícil, decantada no melhor da arte brasileira, é indicativa da constituição de uma forma adequada à experiência nacional diferencial -, conseguiram discutir e esquadrinhar as linhas evolutivas da experiência nacional pela via do mundo das formas artísticas. Posto que, salvo engano, ao modo do Ser em 
Aristóteles (ArANTES, 2004, p. 59), a indecorosa ligação e síntese entre civilidade e barbárie, ocorrida por essas bandas, pode ser dita em vários sentidos.

\section{REFERÊNCIAS BIBLIOGRÁFICAS}

Adorno, Theodor W. Filosofia da nova música. São Paulo: Perspectiva, 2011. . Teoria estética. Lisboa: Edições 70, 1970.

Amaral, Aracy A. Artes plásticas na semana de 22. São Paulo: Editora 34, 2010.

Arantes, Otília B. F. Notas sobre o método crítico de Gilda de Mello e Souza. Estudos Avançados, São Paulo, v. 20, n. 56, p. 311-322, 2006.

Arantes, Otília; Arantes, Paulo. O sentido da formação hoje. Praga, São Paulo, número 4, p. 95-109, 1997a.

. Sentido da Formação: Três estudos sobre Antonio Candido, Gilda de Mello e Souza e Lúcio Costa. Rio de Janeiro, Paz e Terra, 1997b.

Arantes, Paulo. "A fratura brasileira do mundo". In: Arantes, Paulo. Zero à esquerda. São Paulo: Conrad Editora do Brasil, 2004, p. 25-79.

Sentimento da dialética na vida intelectual brasileira: dialética e dualidade segundo Antonio Candido e Roberto Schwarz. Rio de Janeiro: Paz e Terra, 1992.

. Um departamento francês de ultramar: estudos sobre a formação da cultura filosófica uspiana (Uma experiência nos anos 6o). São Paulo: Paz e Terra, 1994.

ARGan, Giulio Carlo. Arte moderna: do Iluminismo aos movimentos contemporâneos. São Paulo: Companhia das Letras, 2013.

"David e Roma". In: Argan, Giulio Carlo. A arte moderna na Europa: de Hogarth a Picasso. São Paulo: Companhia das Letras, 2010, p. 244-253.

. História da arte como história da cidade. São Paulo: Martins Fontes, 1988.

Batista, Marta R. Os artistas brasileiros na Escola de Paris: anos 1920. São Paulo: Editora 34, 2012.

BRITo, Ronaldo. Experiência crítica. São Paulo: Cosac Naify, 2005.

Burger, Peter. Teoria da vanguarda. São Paulo: Cosac Naify, 2008.

CAndido, Antonio. "A faculdade no centenário da Abolição". In: CANDido, Antonio. Vários escritos. Rio de Janeiro: Ouro sobre Azul, 2011a, p. 229-243.

Formação da literatura brasileira: momentos decisivos (1750 - 1880). Rio de Janeiro: Ouro sobre Azul, 2013.

Literatura e sociedade. Rio de Janeiro: Ouro sobre Azul, 2011b.

Chauí, Marilena. “A dignidade do feminino”. In: Miceli, Sergio e Mattos, Franklin de. Gilda: a paixão pela forma. Rio de Janeiro: Ouro sobre Azul, 2007, p. 23-51.

FurTado, Celso. Formação econômica do Brasil. São Paulo: Companhia Editora Nacional, 1995. 
Galvão, Walnice N. “Um percurso intelectual”. In: : Miceli, Sergio e Mattos, Franklin de.

Gilda: a paixão pela forma. Rio de Janeiro: Ouro sobre Azul, 2007, p. 51-71.

Gомвгісн, Ernest. "Dá luz à tinta"; "Verdade e estereótipo". In: GoмвRich, Ernest. Arte e Ilusão. São Paulo: Martins Fontes, 1986, p. 27-83.

LukÁcs, Georg. A alma e as formas: ensaios. Belo Horizonte: Autêntica Editora, 2015.

Mаммі̀, Lorenzo. “A forma difícil”. In: Mаммі̀, Lorenzo. O que resta: arte e crítica de arte. São Paulo: Companhia das Letras, 2012, p. 295-299.

Menezes, Paulo. Representificação: as relações (im)possíveis entre cinema documental e conhecimento. Revista brasileira de ciência sociais, nº 51, p. 87-98, 2003.

NAves, Rodrigo. A forma difícil: ensaios sobre arte brasileira. São Paulo: Companhia das Letras, 2011.

. "De relógios, bússolas e sextantes: perguntas a Roberto Schwarz". In: CEvasco, Maria Elisa е ОнатА, Milton (Org.). Um crítico na periferia do capitalismo: reflexões sobre a obra de Roberto Schwarz. São Paulo: Companhia das Letras, 2007, p. $200-212$. . "Entrevista". In: Moura, Flávio; Monteiro, Paula. Retrato de grupo - 40 anos de Cebrap. São Paulo: Cosac Naify, 2009, p. 246-264.

Entrevista com Rodrigo Naves. In: Revista número, $\mathrm{n}^{0}$ 7, 2005. Disponível em: http://www.forumpermanente.org/rede/numero/rev-numero7/entrevRodrigoNav. Acesso em: 05/07/2016.

. O vento e o moinho. São Paulo: Companhia das Letras, 2007.

"Prefácio". In: Argan, Giulio Carlo. Arte moderna: do Iluminismo aos movimentos contemporâneos. São Paulo: Companhia das Letras, 2013, p. XI-XXIV. Prado JR., Bento. "A hermenêutica de Gilda”. In: Miceli, Sergio e Mattos, Franklin de. Gilda: a paixão pela forma. Rio de Janeiro: Ouro sobre Azul, 2007, p. 13-23.

Prado JR., Caio. Formação do Brasil contemporâneo: colônia. São Paulo: Companhia das Letras, 2011.

Pontes, Heloísa. Destinos mistos: os críticos do Grupo Clima em São Paulo de 194O - 1968. São Paulo: Companhia das Letras, 1998. “Gilda de Mello e Souza: entre a arte e a ciência?”. In: Botelho, André e SchwARcz, Lilia (Org.). Um enigma chamado Brasil: 29 intérpretes e um país. São Paulo: Companhia das Letras, 2009, p. 296-310.

Ricupero, Bernardo. Da formação à forma. Ainda as 'ideias fora do lugar'. Lua Nova, $\mathrm{n}^{\mathrm{o}}$ 73, p. 59-69, 2008.

. Formação da literatura brasileira nos anos 1950. Revista Água Viva, v.1, no 1, p. 1-5, 2010.

Schwarz, Roberto. Ao vencedor as batatas: forma literária e processo social nos inícios do romance brasileiro. São Paulo, Ed. 34, $2012 a$. 
. Que horas são?: ensaios. São Paulo, Companhia das Letras, 2012b.

. Sequências brasileiras: ensaios. São Paulo, Companhia das Letras, 2014.

Um mestre na periferia do capitalismo: Machado de Assis. São Paulo, Ed.

34, 2012c.

Souza, Gilda de Mello e. A ideia e o figurado. São Paulo: Editora 34, 2005.

. "Depoimento: Gilda de Mello e Souza”. In: BlaY, Eva Alterman e LANG, Alice

Beatriz da Silva Gordo. Mulheres na USP: horizontes que se abrem. São Paulo:

Humanitas, 2004, p. 61-77.

. Exercícios de leitura. São Paulo, Editora 34, 2008.

O espírito das roupas: a moda no século XIX. São Paulo: Companhia das

Letras, 2001.

Tognolli, Dora; Vergueiro, Francisca V. Entrevista com Rodrigo Naves. IDE, São Paulo, $\mathrm{n}^{\mathrm{o}} 54, \mathrm{p} .19-28,2012$.

WAIzBort, Leopoldo. A passagem do três ao um: crítica literária, sociologia e filologia.

São Paulo: Cosac Naify, 2007. 